\title{
PHYLOGENETIC STUDIES IN EUOENOTHERA ${ }^{\prime}$
}

\author{
Erich Steiner \\ Department of Botany, Lnizersity of Michigan, Ann Arbor, Michigan
}

Received June 18, 1951

\section{INTRODUCTION}

For a number of years Oenothera has been the object of extensive studies utilizing the cytological and genetical peculiarities of the genus to provide an understanding of phylogenetic relationships within the group." The present study, concerned with the cytogenetic analysis of certain races ${ }^{3}$ of Euoenothera from the southeastern United States, represents one contribution to the reconstruction of the phylogenetic history of the group.

The North American emoenotheras belong to two principal cytogenetic types: on the one hand, races occurring primarily in California and Mexico are characterized by seven bivalents at meiosis, open-pollinated flowers, and the absence of lethals. The majority of euoenotheras occurring throughout the central and eastern United States, however, exhibit a circle of fourteen chromosomes at meiosis, balanced lethals, and a self-pollinating habit. Cytogenetic analysis of collections from many parts of the range of this latter group has shown it to be composed of many races differing with respect to the end arrangement of the chromosome sets or "complexes" which they carry. Although there occur many isolated races each composed of two complexes with

1 This paper is from a doctoral thesis submitted to Indiana University in June, 1950. The study was made possible through grants from the Rockefeller Foundation and Indiana Eniversity to Dr. R. E. Cleland for research in Ocnothera cytogenetics. The author is indebted to Dr. Cleland for guidance and encouragement throughout this investigation.

$\because$ For a summary of these studies see Cleland, 1949.

3 The term "race" indicates a line of descent more or less isolated from other lines of descent by the self-pollinating habit. A collection is a sample from the race. dissimilar end arrangements, most of these races can nevertheless be grouped into certain broad categories on the basis of similarities in the segmental arrangement of their complexes. Furthermore, these categories are characterized in a general way by distinctive phenotypic features. These groups have been described by Cleland, 1949. For purposes of this discussion, only three of these need be mentioned here, namely:

Hookeris-These include the California and some Mexican races; they show seven pairs of chromosomes at meiosis and possess large, open-pollinated flowers. The segmental arrangement most commonly encountered in this group is : $1 \cdot 23 \cdot 45 \cdot 6$ $7 \cdot 109 \cdot 811 \cdot 1213 \cdot 14$. This arrangement is considered to be ancestral for the euoenotheras.

Strigosas-These races range from the Rocky Mountains east to the Mississippi Valley and northwestward to the Pacific Coast. In appearance they are thickleaved, grayish, with appressed pubescence; the two complexes have similar phenotypic effects. The alpha complexes (transmitted through the egg) are similar to each other in segmental arrangement: the beta complexes (transmitted through the pollen) are also similar to each other. The alpha complexes are very different in segmental arrangement from the beta complexes, however, although both are related to the ancestral arrangement, differing from the latter by about three interchanges on the average.

Biennis group 1-These are forms with broad, thin, crinkly leaves occurring from the Ozark region eastward through the Alleghenies to the Atlantic Coast in the region of Virginia: the distinctive phenotype of the group is carried by the alpha complexes. The beta complexes are typi- 
cal strigosa-like complexes, which are, however, rather completely masked in the races themselves. Most of the alpha complexes of this group are only one interchange removed from the ancestral arrangement. The beta complexes are more closely related to the beta strigosas.

In the earlier work few collections from the southeastern United States had been analyzed cytogenetically; the results indicated the presence in this region of several types whose relationships were not obvious. The present investigation was undertaken to bring additional collections into the picture in order to determine the relationships of the southeastern euoenotheras.

\section{Materials and Methods}

The new races which have been analyzed in this study are listed in table I. Each of these was hybridized with a series of "standard" races, whose complexes were known in regard to segmental arrangement and the phenotypic characters which they produced. Deter- mination of the meiotic chromosomal configurations of the hybrids provided the data from which the segmental arrangements of the complexes occurring in the new races were worked out. All cytological material was prepared according to the schedule described by Hecht, 1950 . From analysis of the hybrid phenotypes, it was possible to determine the phenotypic characters which the new complexes produce.

\section{Results}

The newly determined segmental arrangements of the complexes studied are listed in table II. Limitations of space prohibit presentation of the hybrid chromosomal configurations as well as the reasoning which was used in working out these segmental arrangements. Descriptions of each race are also omitted. The complete cytological data and analysis along with the descriptions of the races are available in the thesis at the Indiana University library. The pertinent morphological features of the races and their component complexes must be mentioned

TABLE I. New races included in the present study

\begin{tabular}{|c|c|c|c|c|}
\hline Race & Source & Collector & Year & $\begin{array}{l}\text { Chromosome } \\
\text { configuration }\end{array}$ \\
\hline Alabama & $\begin{array}{l}\text { University of } \\
\text { Alabama campus, } \\
\text { University, Ala. }\end{array}$ & R. M. Harper & 1947 & 7 pairs \\
\hline Athens $A$ & $\begin{array}{l}11 \text { miles north of } \\
\text { Athens, Jackson } \\
\text { Co., Georgia }\end{array}$ & A. Cronquist & 1947 & $\odot 14$ \\
\hline Athens $B$ & $\begin{array}{l}11 \text { miles north of } \\
\text { Athens, Jackson } \\
\text { Co., Georgia }\end{array}$ & A. Cronquist & 1947 & $\odot 14$ \\
\hline Alhens $C$ & $\begin{array}{l}11 \text { miles north of } \\
\text { Athens, Jackson } \\
\text { Co., Georgia }\end{array}$ & A. Cronquist & 1947 & $\odot 14$ \\
\hline Athens $D$ & $\begin{array}{l}11 \text { miles north of } \\
\text { Athens, Jackson } \\
\text { Co., Georgia }\end{array}$ & A. Cronquist & 1947 & $\odot 14$ \\
\hline Biloxi & Biloxi, Miss. & P. A. Munz & 1935 & $\odot 14$ \\
\hline Citronelle & $\begin{array}{l}\text { Citronelle, Mo- } \\
\text { bile Co., Ala. }\end{array}$ & P. A. Munz & 1935 & $\odot 14$ \\
\hline Tuscaloosa $A$ & $\begin{array}{l}\text { Roadside east of } \\
\text { Tuscaloosa, Ala. }\end{array}$ & B. Williams & 1946 & $\odot 14$ \\
\hline $\begin{array}{l}\text { Tuscaloosa } B \\
\text { Tuscaloosa } C\end{array}$ & $\begin{array}{l}\text { Tuscaloosa, Ala. } \\
\text { Tuscaloosa, Ala. }\end{array}$ & $\begin{array}{l}\text { B. Williams } \\
\text { R. M. Harper }\end{array}$ & $\begin{array}{l}1946 \\
1947\end{array}$ & $\begin{array}{l}\odot 14 \\
\odot \\
\odot\end{array}$ \\
\hline Tensaw & Tensaw, Ala. & P. A. Munz & 1938 & $\odot 14$ \\
\hline
\end{tabular}


TABLE II. Segmental arrangements of complexes in southeastern euoenotheras and their relatives

\begin{tabular}{|c|c|c|c|c|c|c|c|}
\hline \multicolumn{8}{|c|}{ Alpha and haplo-complexes } \\
\hline${ }^{*}$ neo-acuens & 1.13 & 3.2 & 5.6 & 7.10 & 9.8 & 11.12 & 4.14 \\
\hline *acuens & 1.4 & 3.2 & 5.6 & 7.10 & 9.8 & 11.12 & 13.14 \\
\hline${ }^{*}{ }_{\alpha B \text { Blloxi }}$ & 1.2 & 3.4 & 5.10 & 7.6 & 9.8 & 11.12 & 13.14 \\
\hline *hDixie Landing & 1.2 & 3.4 & 5.6 & 7.10 & 9.8 & 11.12 & 13.14 \\
\hline${ }^{n}$ Alabama & 1.2 & 3.4 & 5.6 & 7.10 & 9.8 & 11.12 & 13.14 \\
\hline$\alpha T$ uscaloosa $A$ & 1.2 & 3.4 & 5.14 & 7.10 & 9.8 & 11.12 & 13.6 \\
\hline$\alpha T$ Tscaloosa $B$ & 1.2 & 3.4 & 5.14 & 7.10 & 9.8 & 11.12 & 13.6 \\
\hline$\alpha$ Tuscaloosa $C$ & 1.2 & 3.4 & 5.14 & 7.10 & 9.8 & 11.12 & 13.6 \\
\hline$\alpha$ Tensaw & 1.2 & 3.4 & 5.14 & 7.10 & 9.8 & 11.12 & 13.6 \\
\hline$\alpha A$ thens $B$ & 1.2 & 3.4 & 5.14 & 7.10 & 9.8 & 11.12 & 13.6 \\
\hline$\alpha$ Athens $D$ & 1.2 & 3.4 & 5.14 & 7.10 & 9.8 & 11.12 & 13.6 \\
\hline$*_{\alpha}$ Citronelle & 1.2 & 3.4 & 5.14 & 7.9 & 8.10 & 11.12 & 13.6 \\
\hline$\alpha$ Athens $A$ & 1.4 & 3.10 & 5.13 & 7.2 & 9.8 & 11.12 & 14.6 \\
\hline$\alpha .4$ thens $C$ & 1.4 & 3.10 & 5.13 & 7.2 & 9.8 & 11.12 & 14.6 \\
\hline \multicolumn{8}{|l|}{ Beta complexes } \\
\hline *truncans & 1.13 & 3.7 & 5.2 & 4.6 & 9.14 & 11.10 & 8.12 \\
\hline$B$ Athens $A$ & 1.13 & 3.7 & 5.2 & 4.6 & 9.14 & 11.10 & 8.12 \\
\hline$\beta A$ thens $B$ & 1.13 & 3.7 & 5.2 & 4.6 & 9.14 & 11.10 & 8.12 \\
\hline BAthens $D$ & 1.13 & 3.7 & 5.2 & 4.6 & 9.14 & 11.10 & 8.12 \\
\hline${ }^{*} \beta$ Warrenton & 1.13 & .3 .7 & 5.2 & 4.6 & 9.14 & 11.10 & 8.12 \\
\hline * BLaCrosse & 1.13 & 3.6 & 5.2 & 7.4 & 9.14 & 11.10 & 8.12 \\
\hline * BMagnolia & 1.13 & 3.9 & 5.2 & 4.6 & 7.14 & 11.10 & 8.12 \\
\hline BAthens $C$ & 1.13 & 3.6 & 5.7 & 4.8 & 9.14 & 11.10 & 12.2 \\
\hline$\beta T$ uscaloosa $A$ & 1.13 & 3.2 & 5.7 & 4.8 & 9.12 & 11.10 & 14.6 \\
\hline$\beta T$ uscaloosa $B$ & 1.4 & 3.7 & 5.11 & 6.10 & 9.2 & 8.12 & 13.14 \\
\hline$\beta T$ uscaloosa $C$ & 1.4 & 3.7 & 5.11 & 6.10 & 9.2 & 8.12 & 13.14 \\
\hline BTensaw & 1.4 & 3.7 & 5.11 & 6.10 & 9.2 & 8.12 & 13.14 \\
\hline$\beta$ Citronelle & 1.4 & 3.13 & 5.9 & 7.2 & 11.6 & 8.12 & 10.14 \\
\hline$\beta B$ iloxi & 1.10 & 3.5 & 7.14 & 9.6 & 11.2 & 8.12 & 13.4 \\
\hline \multicolumn{8}{|c|}{ Complexes with arrangements related to the above complexes } \\
\hline${ }^{*} \beta$ Rich Mountain & 1.4 & 3.7 & 5.11 & 6.10 & 9.2 & 8.12 & 13.14 \\
\hline${ }^{*} \beta$ Birch Tree 1 & 1.4 & 3.13 & 5.7 & 6.11 & 9.10 & 8.12 & 14.2 \\
\hline *BBirch Tree 2 & 1.13 & 3.2 & 5.7 & 4.12 & 9.6 & 11.10 & 8.14 \\
\hline$*_{\alpha G o t h e n b u r g}$ & 1.10 & 3.12 & 5.8 & 7.2 & 9.6 & 11.4 & 13.14 \\
\hline \multicolumn{8}{|c|}{$\begin{array}{l}\text { Most common alpha biennis } \\
\text { group } 1 \text { arrangement }\end{array}$} \\
\hline & $\begin{array}{l}\mathrm{nt} \\
1.2\end{array}$ & 3.4 & 5.14 & 7.10 & 9.8 & 11.12 & 13.6 \\
\hline
\end{tabular}

* Determined in earlier studies.

in the discussion of their relationships which follows; it therefore seems superfluous to present them here also.

\section{Discussion}

In these studies similarity in segmental arrangement is taken as the primary clue to phylogenetic affinity. Inspection of table II reveals that a number of the complexes are identical in segmental arrangement, and a close similarity exists between others. These similarities, when corre- lated with morphological and geographical data suggest that the southeastern euoenotheras should be classified into two primary groups. The first group (I) consists of races which show both segmental and morphological affinities to the biennis group 1 races. This group may be subdivided into two series one of which (a) consists of races from Alabama which are more or less identical morphologically with the midwestern biennis group 1; the other series (b) includes forms from 
Georgia, which, although biennis-like, possess narrower leaves and a less branched habit than is characteristic of the typical biennis group 1 races. The second major group (II) includes the large-flowered, open pollinated, narrowleaved forms which have been known to most botanists as Oe. grandiflora Ait. In addition, one race, collected at Biloxi, Mississippi, cannot be placed in either of the major groups, although it shows a distinct affinity to the grandiflora group.

In the following presentation, each of these groups will be dealt with separately. The cytological and morphological features which characterize the races belonging to a specific group as well as their geographical distribution will be stummarized. The phylogenetic significance of these data is then discussed in the case of each group.

\section{I. (a) Biennis races from Alabama}

The three Tuscaloosa races, Tensaze, and Citronelle belong in this category. These races possess the following phenotypic characters: moderately broad, dark to light green, somewhat crinkled, moderately thick leaves with erect to suberect hairs: stems with a moderate to strong basal color: usually a well developed central shoot with considerable branching; small, self-pollinated flowers. The races Tuscaloosa $B$ and $C$, and Tensaw also have red leaf margins, stem tips, hypanthia, and cones, and are almost identical in appearance. Green leaf margins, stem tips, hypanthia, and bud cones readily distinguish Tuscaloosa $A$ from these races. Citronelle, which is the least typical nember of this group, has brilliantly reddened stem tips, but green leaf margins, hypanthia, and bud cones; it further differs from the others in possessing somewhat narrower leaves and a less pronounced central shoot tendency. Each of these races is a complex heterozygote with a circle of 14 chromosomes at meiosis.

Alpha complexes. With the exception of alpha Citronelle, all of the alpha com- plexes of this group are identical in segmental arrangement. Of especial interest is the fact that this particular arrangement is characteristic of the alpha biennis group 1 complexes. Alpha Citronelle, which does not possess this same arrangement, is however, only one interchange removed from it. Instead of having $7 \cdot 10$ and $9 \cdot 8$, it has $7 \cdot 9$ and $8 \cdot 10$. From the standpoint of segmental arrangement, therefore, the alpha complexes of this series of races show the highest degree of relationship, not only to each other, but also to the great majority of the alpha biennis 1 complexes.

The phenotypic effects produced by alpha Tuscaloosa $A, B$, and $C$, alpha Tensaw, and alpha Citronelle are essentially biennis-like, although they may differ in minor characteristics. These complexes, in general, carry factors for fairly broad, dark green, somewhat crinkled, thin leaves, considerable branching, rather slender, tapered bud cones, and erect bracts. The similarity in regard to phenotypic effect of these complexes to those of the alpha biennis group 1 is striking: these phenotypic effects are all more or less characteristic of the alpha biennis 1 complexes. There is, therefore, no segmental or phenotypic distinction between the alpha complexes of this southern group and those of the midwestern biennis 1 category.

Beta complexes. The segmental arrangements of three beta complexes, beta Tuscaloosa $B$ and $C$, and beta Tensaw are identical. This particular arrangement also occurs in the beta complex of Rich Mountain, a biennis group 1 race from Arkansas. The remaining two races, Tuscaloosa $A$ and Citronelle, have beta complexes which are a minimum of six and four interchanges removed, respectively, from the beta Rich Mountain arrangement. These beta complexes, however, show close segmental relationships to other beta biennis 1 complexes; beta Citronelle is only two interchanges removed from beta Birch Tree 1, while beta Tuscaloosa $A$ is two interchanges distant 
from beta Birch Tree 2. Both Birch Tree races occur in southern Missouri and belong to the biennis group 1. Thus, although the beta complexes of these Alabama races lack the degree of segmental uniformity shown by the alpha complexes, they do, nevertheless, show affinities to the beta biennis 1 complexes, so far as segmental arrangement is concerned.

The morphological characters which are produced by the beta Tuscaloosa $A$, $B$, and $C$, Tensaw, and Citronelle complexes are essentially strigosa-like. These complexes produce narrow, gray green, thick leaves with appressed pubescence, a strict habit with little branching, flaring bracts, and thick, rather short bud cones. The same morphological features characterize the beta bicunis 1 complexes. The morphological similarity of these two groups of beta complexes further strengthens the conviction that they are closely related.

Geographical distribution. Those midwestern biennis group 1 races which show the closest affinities to the Alabama biennis forms occur in Arkansas and southern Missouri. The Tuscaloosa races were collected in west central Alabama, while Tensaw and Citronclle were obtained from two distinct localities in southwestern Alabama. Hence, the range of the Alabama races can be considered as more or less continuous with that of the midwestern forms. Whether similar forms occur farther east in Georgia, Florida, and South Carolina cannot yet be determined in the absence of more numerous collections from this area.

The Alabama biennis races are linked to their southern habitat by two distinctive features: they do not form an appreciable rosette, ${ }^{4}$ nor do they bloom until late in the season. They are short day plants.

Relationships of the Alabama biennis forms. The foregoing evidence appears overwhelmingly in favor of interpreting

${ }^{4}$ At least under garden conditions in Indiana, in contrast to the midwestern biennis group 1 races. these races as typical biennis group 1 forms. The races are biennis in appearance; they possess alpha complexes which carry factors for a biennis phenotype, and these are associated with beta complexes producing strigosa characters. Segmentally, the alpha complexes are identical, or in one case only one interchange removed, with the segmental arrangement characteristic of the midwestern alpha biennis 1 complexes. The beta complexes, although in only three cases segmentally identical with one of the midwestern beta biennis arrangements, nevertheless, show close relationships to the latter group. In addition, the range of the southern forms is contiguous with that of the midwestern races. For these reasons, the Alabama biennis forms are considered to belong to the biennis group 1 category and their presence in Alabama constitutes an extension of the range of biennis group 1.

\section{I. (b) Biennis-like races from Georgia}

Included in this category are four races collected near Athens, Georgia. These small flowered, self-pollinated forms, although more or less biennis-like in appearance, are separated from the Alabama biennis group because they display certain modifications of the typical biennis phenotype. They possess somewhat narrower, lighter green leaves, longer internodes, a stricter habit, and are less branched. Each race is a complex heterozygote with a circle of 14 chromosomes at meiosis.

Alpha complexes. Alpha Athens B and $D$ are identical in segmental arrangement with the typical alpha biennis 1 complexes. Alpha Athens $A$ and $C$, which are identical in segmental arrangement, are only three interchanges removed from the most common alpha biennis 1 arrangement. Segmentally, these alpha complexes, therefore, show a distinct affinity to the alpha biennis group 1 .

In regard to phenotypic effect, the alpha Athens complexes produce characters, which, while biennis-like, tend to 
lean toward a type with slightly narrower, less crinkled, somewhat thicker leaves.

Beta complexes. The phenotypic effects produced by the four beta Athens complexes are similar; these include narrow, short, grayish green, strongly wavy, thick leaves, a strict habit with little branching, flared bracts, and a rather stout, thick-skinned bud cone. Although the general effect is strigosa-like, it differs from a typical strigosa phenotype in the shorter, stiffer, narrower leaves. These differences are in part responsible for the deviation of these races from a typical biennis group 1 phenotype.

Although the alpha complex of Athens $A$ is identical segmentally with the alpha of Athens $C$, the beta complex of Athens $A$ is identical in segmental arrangement with beta Athens $B$ and $D$. The segmental arrangement of beta Athens $C$, however, is three interchanges removed from that of beta Athens $A, B$, and $D$.

It will be noted (Table II) that the arrangement found in the latter three complexes occurs rather widely among races from the southeast as well as from the eastern part of the biennis group 1 range. This arrangement was first found in the truncans complex of the grandiflora of deVries, a race which will be discussed later in connection with the grandiflora group. Two races occurring in Virginia, Warrenton and Charlottesrille, each possess one complex with the truncans arrangement. In the former race the beta complex, in the latter, the alpha complex exhibits this arrangement. In addition, the arrangements of the beta complexes of LaCrosse, a race from Virginia, and Magnolia, a race from Kentucky, are each one interchange removed from the truncans arrangement.

Relationships of the Athens races. The characteristics of the Athens races outlined in the foregoing paragraphs suggest two tentative conclusions in regard to the phylogenetic affinities of this group. First, the Athens group shows a distinct relationship to the biennis group 1 . On the other hand, the widespread occurrence of complexes with the truncans or modified truncans arrangement suggests that the races which carry such complexes represent a distinct phylogenetic grouping to which the Athens races belong.

Considerable evidence exists which relates the Athens forms to biennis group 1. The Athens races are biennis-like in appearance. They possess alpha complexes which produce biennis-like phenotypes and which have segmental arrangements identical with, or closely related to, the typical alpha biennis 1 arrangement. The beta complexes, although at least four interchanges removed from the typical beta biennis 1 arrangements, produce strigosa-like characters which are somewhat similar to those produced by typical beta biennis 1 complexes. Furthermore, the Athens races occur toward the margins of the biennis group 1 range. The distinction between the Athens races and the biennis group 1 forms depends, therefore, primarily on the rather limited phenotypic and segmental differences between the beta complexes of the two groups.

The fact that the modified strigosa phenotype found in the beta Athens complexes is correlated with a distinctive segmental arrangement suggests that these races belong to a phylogenetic entity which is distinct from the biennis group 1. The races Warrenton, LaCrosse, and Magnolia, which also possess beta complexes showing the truncans or modified truncans arrangement, exhibit certain phenotypic similarities to the Athens races. They are, like the Athens races, narrow leaved, biennis-like in appearance; their alpha complexes belong to the alpha biennis group 1, both from the standpoint of phenotype as well as segmental arrangement. The beta complexes, like the beta Athens complexes, although similar to the beta biennis 1 complexes in phenotype, do not produce a typical strigosa phenotype. Moreover, Warrenton, LaCrosse, and Magnolia occur toward the eastern limits of the biennis group 1 range. 
In the light of the above facts, Warrenton, LaCrosse, Magnolia, and the Athens races are considered to be outlying biennis group 1 forms, which have become differentiated from the typical biennis 1 type both phenotypically and segmentally. The truncans arrangement, arising through a series of interchanges among the beta biennis 1 complexes and concurrently accumulating genetic factors having adaptive value in the southeastern area, has become characteristic of a population of Euoenothera in this region. The extent to which the truncans arrangement is distributed among the southeastern biennislike forms can only be determined by the analysis of additional races from this area. More knowledge concerning the distribution of this arrangement may also throw light on its manner of origin among the beta biennis 1 arrangements.

It is of interest to note that there is also some evidence of relationship between the Athens races and the Alabama biennis group. Apart from the segmental and phenotypic similarity of the alpha complexes of these two groups, relationship is also indicated by the fact that beta Tuscaloosa $A$ has a segmental arrangement only three interchanges removed from beta Athens $A$, and only two interchanges removed from beta Athens $C$. It will be remembered that beta Tuscaloosa $A$ differs from the other two beta Tuscaloosa complexes in phenotype and segmental arrangement. This race may represent an intermediate form between the typical biennis forms and those, like the Athens group, which have become modified. It is difficult to determine, however, whether such an apparently intermediate form does actually represent a stage in the sequence of development of one phylogenetic grouping from another.

\section{Grandifiora group ${ }^{5}$}

This southern group is represented in our collections by Dixic Landing, Ala-

\footnotetext{
5 The name grandiflora is used to designate a phylogenetic grouping except in those cases where it is followed by "(deVries)" when it
}

bama, and the grandiflora of delries. These races are characterized by large, open-pollinated flowers, rather narrow, dark to light green, snooth leaves, few short, erect hairs, erect bracts, and glabrous, green capsules. Unlike other forms of Euoenothera, the grandifloras have distinctly fragrant flowers. Other characters may differ from race to race so that each race has a distinctive appearance. For example, Dixie Landing has deeply lobed leaves and a spreading habit. Alabama, on the other hand, has evenly and finely toothed leaf margins and exhibits a low, compact habit unlike that found in any other Euoenothera of our collection. Dixie Landing and Alabama are races with all pairing chromosomes and no lethals. Grandiflora (deVries), however, is a complex heternzygote with a circle of 14 chromosomes and balanced lethals. ${ }^{6}$

Both 'Dixie Landing ${ }^{\mathrm{T}}$ and ${ }^{\mathrm{h}}$ Alabama possess the segmental arrangement which is considered ancestral among the North American euoenotheras, namely, $1 \cdot 23 \cdot 4$ $5 \cdot 67 \cdot 109 \cdot 811 \cdot 1213 \cdot 14$. Since these races are homozygous, the phenotypic effects of their complexes are fully shown in the races themselves.

On the other hand, grandiflora (deVries), a complex heterozygote is com-

applies to the race collected by deVries. As the discussion will reveal, this phylogenetic grouping is not identical with Oe. grandiflora Ait., since the latter may include certain types excluded from the former on the basis of cytogenetic characteristics.

B The grandiflora of deVries when originally received in our collection had $\odot 14$, its complexes being acuens and truncans (Hoeppner and Renner, 1928; Gerhard, 1929). As a result of interchange occurring in the experimental garden, the race as now grown has $\odot 12,1$ pair; the $\odot 14$ form has been lost. The complex resulting from this interchange is called neo-acuens, since it is one interchange removed from acuens. The possible origin of neo-acuens is discussed by Cleland, 1950. For the sake of simplicity, grandiflora (deVries) will be considered as a $\odot 14$ form in the current discussion.

- The superscript " $h$ " is used before a complex which is present in double dose in a complex homozygote. 
posed of the two complexes, acuens and truncans. The acuens arrangement is one interchange removed from the ancestral arrangement, having $1 \cdot 4$ and $3 \cdot 2$ instead of $1 \cdot 2$ and $3 \cdot 4$. Acuens is, therefore, closely related segmentally to ${ }^{\mathrm{h}}$ Dirie Landing and ${ }^{\mathrm{h}}$ Alabama. Furthermore, acucns produces a phenotype characterized by large flowers, narrow leaves, and erect bracts which is similar to that of the homozygous grandiflora races. The truncans complex, although producing a grandiflora phenotype, is, nevertheless, far removed segmentally from the ancestral arrangement.

Since the truncans arrangement has been encountered in the Athens races, it appears that grandiflora (deVries) is a hybricl between a homozygous grandiflora race such as Dirie Landing or Alabama and a race similar to the Athens forms, the former contributing the acuens complex, the latter the truncans complex. That such a hybrid could occur is not unlikely, since Bartlett and deV ries (1912) have described numerous biennis-like types growing together with the grandifloras in the native habitat of the latter group. This explanation unfortunately has one difficulty; truncans produces a phenotype very similar to that of acuens and not the same phenotype associated with the truncans or modified truncans arrangement in the Athens races, Warrenton, LaCrosse, and Magnolia. The beta complexes of the latter races do share in common with the truncans of grandiflora (deVries) certain features such as narrow leaves, strict habit, and flaring bracts. Truncans, however, produces darker green, less wavy, thinner leaves and large flowers in contrast to the gray green, thick, wavy leaves and small flowers of the other complexes. If truncans and the other complexes showing the truncans or slightly modified arrangements are as closely related as similarity in segmental arrangement seems to indicate, then an explanation for a modification to the truncans phenotype is in order. The factor for large flowers could have easily been acquired from acuens as a result of crossing over, since this gene, located near the end of the chromosome, shows 50 per cent crossing over (Emerson and Sturtevant, 1932). There is no evidence, however, as to whether the other grandiflora characters could have been transferred to truncans in the same manner. Whatever the explanation, it seems probable that grandiflora (deVries) is not typical, at least cytogenetically, of the grandiflora population as it exists in nature. The true grandifloras appear to be complex homozygotes; the grandiflora of deVries is a complex heterozygote with one grandiflora complex and another complex which is phenotypically grandiflora but segmentally of a different origin. Further work will be necessary before the affinities of truncans are understood.

Geographical distribution of the grandifloras. William Bartram first observed Oe. grandiflora Ait. in 1778, when he found it growing at Dixie Landing on the Alabama River near Tensaw, Alabama. ${ }^{8}$ This locality was rediscovered by Tracey in 1904 (Bartlett and deVries, 1912). The race, Dixie Landing, although collected on the University of Alabama campus where it was under cultivation, is known to have descended from plants obtained from the Dixie Landing habitat. Whether Alabama, which was also obtained on the University of Alabama campus, was originally collected at Dixie Landing is not known; it seems likely, however, that this is the case, since there is no record that the grandiflora types are also native to the Tuscaloosa area. The other grandiflora race in our collection, grandiflora (deVries) was collected at Castleberry, Alabama, not far from Tensaw. Thus the grandiflora forms appear to be native to a single locality in southern Alabama. There is at present no evidence that the grandifloras occur in any other area in the Southeast, although an intensive field survey of the entire

\footnotetext{
8 Bartram, William. The travels of William Bartram. Edited by Mark van Doren. New York, 1940.
} 
region might reveal additional habitats of these forms. Even if the grandifloras were found elsewhere, the possibility that they represent escapes from cultivation would have to be considered. Gray's Manual states that the grandifloras were formerly cultivated and occur occasionally as escapes.

Relationships of the grandifloras. What is, then, the position of the grandifloras in the phylogenetic pattern of the North American euoenotheras? The limited distribution of the grandifloras has been interpreted by Bartlett ${ }^{\circ}$ as evidence that they represent the remains of an older, once widely distributed population. This hypothesis finds support in a number of facts. In the first place, these forms show an ancestral segmental arrangement; from this standpoint they must be considered primitive. The phenotypic character of the grandifloras except for the large, open-pollinated flowers is, however, quite different from that found among the hookeris, a fact which would appear to deny the close relationship indicated by the cytological evidence. On the other hand, there is a possibility that the grandifloras are relics of a population which spread from the Southwest at a time when conditions were considerably moister than they are at the present time. There is some evidence (Antevs, 1928; Mayr, 1945) that during the Pleistocene period the climate throughout the Southwest was more generally moist than at present and that those regions which are now deserts may have supported a mesophytic flora. The grandifloras, which are mesophytic in character, may have been a segment of such a population which ranged throughout this area and spread southeastward. As the climate of the Southwest changed from a mesophytic to a xerophytic one, those variants which were better adapted to the drier climate survived in the Southwest. In the Southeast, where the climate remained moist, the mesophytic types persisted. The isolation which was thus established between

\footnotetext{
${ }^{9}$ Conversation with Prof. H. H. Bartlett.
}

the two groups, provided an opportunity for further differentiation and divergence of the two groups. The grandiflora races in our collection show considerable morphological variability: Bartlett and deVries (1912) have described seven ditferent grandiflora types in regard to such characters as cone color, capsule length, pubescence, and leaf margins. Such variability is additional evidence that the grandifloras represent an older group of euoenotheras.

Why are the grandifloras confined to a single locality at present? What is the relationship of the grandifloras to the biemnis forms which occur in the same and neighboring areas? From the standpoint of segmental arrangement, the grandiflora complexes are only one interchange removed from most of the alpha biennis 1 complexes, thus indicating a close relationship between these groups of complexes. This relationship is further substantiated by the phenotypic effects produced by the grandiflora and alpha biennis 1 complexes. The grandiflora complexes produce essentially a biennislike phenotype except for their narrow leaves and large flowers: in fact, the grandifloras have been considered to be merely a variety of the biennis type (Lindley, 1833). Furthermore, the alpha Athens complexes produce a phenotype which is more or less intermediate between a strong biennis and a grandiflora type. These alpha complexes carry factors for narrower, less crinkled leaves than found in the typical midwestern alpha biennis 1 complex. There is, therefore, both morphological and cytological evidence of relationship between the grandiflora and alpha biennis 1 complexes.

Such a relationship provides a clue to the possible origin of the alpha biennis 1 complexes. Cleland (1949), in discussing the origin of the alpha and beta bicmis 1 complexes, states, "The beta complexes may be derived from the beta strigosas, but the origin of the alpha complexes is not so clear. They may represent an earlier indigenous population 
which crossed with the later invading strigosas." The evidence of both morphological and cytological affinity between the grandiflora and alpha biennis 1 complexes suggests that the grandifloras may represent a southern derivative, the alpha biennis 1 complexes a northern offshoot of the "earlier indigenous population" to which Cleland refers. If this population originally spread from the Southwest into the Midwest and East, it is probable that on the northern limits of its range it contacted the strigosas which were invading the Midwest from the Plains region. Hybridization occurring between the two groups then produced a biennis group 1 type. To the south segments of this same population became modified toward the grandiflora phenotype. Thus, through this earlier population it is possible to relate the alpha biennis 1 complexes to the grandifloras as well as to the ancestral California forms, an affinity indicated by the close similarity of the alpha biennis 1 arrangements to the ancestral arrangement.

This hypothesis at the same time provides an explanation for the decline in the geographical range of the grandifloras. With the development of $\odot 14$ biennis forms in the Midwest, the selective advantage generally attributed to the complex heterozygotes allowed these biennis forms to supplant the indigenous races in the Midwest and to invade the southern area occupied by the grandifloras, for the most part supplanting them also. Thus, at the present time, the grandifloras survive in only one known locality, while the common Euoenothera in the South is essentially a biennis type. The grandifloras, therefore, comprise a morphologically distinct group of euoenotheras known to be native only near Tensaw, Alabama. They possess the ancestral segmental arrangement, ${ }^{10}$ indicating relationship to the Cali-

\footnotetext{
10 Since grandiflora (deVries) does not appear to be representative of the grandifloras, at least cytogenetically, discussion of the grandiflara relationships applies only to the homozygous grandifiora races.
}

fornia euoenotheras. Such a relationship suggests the hypothesis that during earlier geologic periods a mesophytic population was distributed from California throughout the Southwest to the Southeast. With climatic changes in the Southwest to a xerophytic habitat, the mesophytic types such as grandiflora persisted only in the Southeast.

In the Midwest where the mesophytic population came into contact with the strigosas moving eastward from the Plains region, the biennis group 1 forms with a circle of 14 chromosomes originated, the alpha biennis 1 complexes being derived from this earlier population and the beta biennis 1 complexes from the beta strigosas. The increased survival value of these complex heterozygotes has allowed the successful extension of their range throughout the Midwest and into the Southeast. The grandifloras, on the other hand, where no longer able to maintain themselves in competition with the biennis races and now exist only as a relic population in one locality in Alabama.

\section{Unclassified forms}

Although the race Biloxi, collected at Biloxi, Mississippi, cannot be placed in either the southern biennis or the grandiflora category, it does show a definite relationship to the latter group. In appearance, Biloxi is a grandiflora form except for its small, self-pollinated flowers. It is a complex heterozygote with a circle of 14 chromosomes at meiosis.

Analysis of its complexes has revealed that the alpha complex carries the factors producing the grandiflora phenotype displayed by the race. In addition, the alpha complex possesses a segmental arrangement only one interchange removed from the ancestral arrangement found in the yrandiflora complexes. Instead of 5.6 and $7 \cdot 10$, alpha Biloxi has $5 \cdot 10$ and $7 \cdot 6$. For these reasons, alpha Biloxi is classified as a grandiflora complex.

Beta Bilori, however, produces a phenotypic effect which is typically strigosa; 
it carries factors for gray green, wavy, thick leaves, appressed pubescence, flared bracts, and stout buds. It is of especial interest that these characters are almost completely masked by the grandifora characters of the alpha complex. In regard to segmental arrangement, beta $B i$ loxi does not show a close affinity to any of the known complexes, with one exception, which produce a strigosa phenotype. It is only three interchanges removed from alpha Gothenburg, one of the alpha strigosa complexes from Nebraska, a fact which may turn out to have some significance. It should be noted, however, that Biloxi is the only collection from Mississippi which has been analyzed; moreover, no races from either Louisiana or Texas have been studied. Thus a relatively large area remains unknown which may contain a group of complexes of which beta Biloxi may be a member. Biloxi probably represents a hybrid between the grandiflora and an unknown Mississippi group. Professor S. M. Tracey, who rediscovered the grandiflora habitat in 1904, introduced these grandifloras into the Biloxi area. ${ }^{11}$ These may have hybridized with forms native to $\mathrm{Bi}$ loxi to produce complex heterozygotes of which our race is representative. A study of other Mississippi races will provide a test for the hypothesis that Biloxi is of recent hybrid origin.

With one exception, therefore, all of the southern euoenotheras so far analyzed fall into two principal phylogenetic groupings. The first of these is a group showing close biennis affinities, the Alabama members of which represent a southern extension of the Midwestern biennis group 1, while the Georgia members so far studied, contain beta complexes which have a distinctive segmental arrangement and a phenotype which is somewhat modified from the typical beta biennis 1 phenotype in the direction of grandiflora. Whether or not the latter category is representative of a widely distributed southern popu-

\footnotetext{
11 Conversation with Prof. H. H. Bartlett.
}

lation showing a regional specificity in regard to segmental arrangement and phenotype can only be determined by the analysis of additional races from the South. As yet, our collection does not include forms from central and southern Georgia, Florida, South Carolina, and eastern North Carolina. A uniform sampling of this area will undoubtedly do much to clarify the status of the modified biennis forms such as the Athens races.

The other principal southern group, the grandiflora assemblage, is in all probability confined to a single locality in southern Alabama, and may represent the remains of an earlier population which was widely distributed throughout the Southeast. These forms are complex homozygotes, whose complexes show relationships both to the hookeris of California and to the midwestern alpha biennis group 1 complexes.

In conclusion, one may ask whether these phylogenetic groupings are useful taxonomic entities. The grandiflora group is certainly morphologically distinct enough to be treated as a separate taxonomic unit. Of the southern group which shows biennis affinities, the Alabama series is difficult to distinguish from the midwestern biennis group 1. To distinguish these forms purely on the basis of geographical distribution does not seem justified. On the other hand, the Georgia races, along with Warrenton, LaCrosse, and Magnolia, show narrow-leaved biennis-like phenotypes which differentiate them from the typical midwestern biennis group 1 forms. Whether these narrow-leaved forms constitute a useful taxonomic entity may be questionable, however, since the differences upon which such a category would le based are not great and have only been observed under standard conditions in the experimental garden. In nature, it is likely that environmental variations may tend to obscure these differences. Further study, involving field surveys, will first be necessary to determine whether the characteristic features of this group are consistently recognizable. 


\section{SUMMARY}

The results of a cytogenetic analysis of ten races of Euoenothera from the southeastern United States are summarized. On the basis of evidence derived from studies of segmental arrangement, morphology, and geographical distribution, the relationships of these races are discussed.

The races from the southeastern Lnited States which have been studied appear to fall into two major phylogenetic groupings. The first group, which shows relationships to the biennis group 1, includes (a) a series of races from Alabama which are identical with the midwestern biennis group 1, and (b) a series from Georgia, which, although biennis-like, shows characters which lean toward the grandiflora phenotype. The second major group consists of large-flowered, narrow-leaved forms which are called grandifloras. The race, Biloxi, although possessing one complex of the grandiflora type, cannot be classified in either of these groups.

The Georgia races are distinguished from the midwestern biennis group 1 primarily by their beta complexes, which differ somewhat from the beta bicnnis 1 complexes in phenotype, and which possess a distinctive segmental arrangement. These races are interpreted as modified biennis group 1 forms which appear to be particularly adapted to the Southeast.

The grandifloras appear to be native to a single locality in southern Alabama. Because the members of this group have all pairing chromosomes which possess the ancestral segmental arrangement also found in the hookeri group, the grandifloras are interpreted as a relic population from a once widely distributed population which originally spread from the Southwest.

On the basis of certain segmental and phenotypic similarities between the grandiflora and alpha biennis group 1 complexes, a hypothesis is suggested to account for the origin of the biennis group 1 forms through hybridization of an earlier population of which the grandifloras are a southern derivative, with strigosalike races moving eastward from the northern Plains region.

Evidence is presented which indicates Biloxi is a hybrid between a grandiflora and a form occurring in Mississippi, which has not yet been analyzed but which may be related to the alpha strigosas.

\section{Literatlire Cited}

Axters, E. V. 1928. The last glaciation. Amer. Geog. Soc., New York.

Bartlett, H. H., ANd deVries, Hugo. 1912. The evening primroses of Dixie Landing, Alabama. Science, 36: 599-601.

BarTRAM, WILliam. 1940. The travels of William Bartram. Edited by Mark van Doren. Facsimile library, New York.

Clemaxd. R. E. 1949. Phylogenetic relationships in Oenothera. Proc. Eighth Int. Cong. Genet., Hereditas, Suppl. Vol.: 173-188. 1950. The origin of neo-acuens. Indiana Univ. Publ. Sci., 16: 73-81.

- ANd B. L. Hammovo. 1950. Analysis of segmental arrangements in certain races of Ocnothera. Indiana Univ. Publ. Sci., 16: 10-72.

Exierson, Sterling, axd A. H. Strrterant. 1932. The linkage of certain genes in Ocuothera. Genetics, 17: 393-412.

Fervald, M. L. 1950. Gray's manual of botany, 8th edition. New York.

Gecki.er, I. H. 1950. The cytogenetic and phylogenetic relationships of certain races of Enoenothera from northeastern North America. Indiana Lniv. Publ. Sci., 16: $160-217$.

Gerh ARd, Kari.. 1929. Genetische und cytologische Untersuchungen an Ocnothera grandiflora Ait. Jena. Zeit. Naturwiss., 64: 283-338.

Hecht, A. 1950. Cytogenetic studies of ()onothera, subgenus Raimamina. Indiana Lniv. Publ. Sci., 16: 255-304.

Hoeppyer, E., and O. Rexier. 1928. Genetische und cytologische Oenotherenstudien. I. Zur Kenntnis der Ocnothera ammophila Focke. Zeit. Ind. Abst. Vererb. 49: 1-25.

Lisdeey, JoHn. 1833. Fdwards" hotanical register. 19: 1604.

Mayr, E. 1945. Symposium on age of the distribution pattern of the gene arrangements in D. pscudoobscura: some evidence in favor of a recent date. L.loydia, 8: 70-83.

Preer, L. B. 1950. A cytogenetic study of certain broad-leaved races of Ocnothera. Indiana Univ. Publ. Sci., 16: 82-159.

VRIES, Hugo DE. 1918. Mass mutation and twin hybrids of Ocnothera grandiffor, Ait. Bot. Gaz., 65: 377-422. 